\title{
Francisco J. Ayala: el hombre renacentista de la evolución. Conversaciones con Ana Barahona
}

\section{Ana Barahona Echeverría}

Arbor CLXVII, 657 (Septiembre 2000), 1-30 pp.

Francisco José Ayala nació en Madrid, España, en 1934. Miembro distinguido de la comunidad científica internacional, se ha destacado por sus estudios en biología evolutiva y en filosofía de la ciencia, mismos que le han valido diversos premios y distinciones académicas como el haber sido Presidente de la Asociación Americana para el Avance de la Ciencia, la asociación científica más importante del mundo y de ser miembro del «Consejo de Asesores de Ciencia y Tecnología» del Presidente W. Clinton.

Desde muy joven se interesó por la ciencia y decidió estudiar física, además, $\mathrm{y}$, como producto de sus inclinaciones filosóficas y religiosas, decidió también estudiar teología. Una vez terminados estos estudios Francisco decidió estudiar la evolución e inició sus estudios doctorales en los Estados Unidos en 1961 en el laboratorio de uno de los más grandes evolucionistas de todos los tiempos, Theodosius Dobzhansky. Desde entonces ha vivido en Estados Unidos y desde 1971 lo ha hecho como ciudadano estadounidense.

Colaborador y amigo de los evolucionistas más importantes de este siglo como Theodosius Dobzhansky, Ernst Mayr, Ledyard Stebbins y George G. Simpson, mejor conocidos como los «arquitectos" de la síntesis moderna, de quienes guarda no sólo recuerdos personales sino una gran admiración. En su laboratorio en el Departamento de Ecología y Biología Evolutiva de la Universidad de California, en Irvine, trabajan estudiantes, técnicos, profesores visitantes y estudiantes de posdoctorado de varios países del mundo, en diferentes proyectos que van desde los estudios de biología molecular, hasta estudios históricos y filosóficos.

Conocí a Francisco en el año de 1990 cuando fue invitado por la Academia de la Investigación Científica (ahora Academia Mexicana de Cien- 
cias) a México, a dar una serie de conferencias sobre el tema «Las Fronteras de la Biología», programa que era compartido por la National Academy of Sciences de Estados Unidos de la que él es miembro. En una visita posterior a México ese mismo año, Francisco aceptó mi invitación a ofrecer una par de conferencias en el Instituto de Investigaciones Filosóficas y en la Facultad de Ciencias, ambas dependencias de la Universidad Nacional Autónoma de México, a las que él asistía por primera vez; durante esta corta estancia tuve la oportunidad de introducirlo con algunos amigos y colegas que se dedicaban a la biología evolutiva y/o a la filosofía de la ciencia, y que conocían a Francisco sólo gracias a su conocido prestigio, y a los cuales dió mucho gusto conocerlo. Desde entonces, las visitas de Francisco a la UNAM han sido frecuentes y siempre han resultado en un gran apoyo.

Tuve la oportunidad de trabajar en su laboratorio desde 1993, año en que realicé mi primera visita a California. Francisco J. Ayala es conocido como un buen jefe y amigo; sus colaboradores y estudiantes guardan no sólo enseñanzas académicas diversas tanto en aspectos teóricos $\mathrm{y}$ prácticos de la ciencia, sino también buenos recuerdos de la vida en uno de los mejores laboratorios del mundo.

Conocido también por sus intereses serios sobre la música, el arte, la historia y por su voracidad como lector de libros sobre temas muy diversos, Francisco ha sido descrito en un artículo recientemente publicado sobre él en The New York Times como el «Renaissance Man of Evolutionary Biology».

Esta entrevista está dividida en tres partes. En la primera de ellas hablamos sobre su formación, sus gustos y sus inclinaciones filosóficas. En la segunda, platicamos acerca de sus inquietudes como científico y de las preguntas que a lo largo de su carrera se ha planteado en la biología evolutiva. En la tercera, conversamos acerca de sus relaciones con otras personas y de científicos a los que él admira.

(Ana) ¿Cómo es que te introdujiste en el mundo de la ciencia, particularmente con tú formación de religioso?

(FJA) Hay dos estadios en eso, primero, mi interés por la ciencia se inició al nivel de lo que se llamaría Junior High School, con un profesor de "ciencias naturales" (que es lo que como se llamaba la asignatura a ese nivel) pero que tenía de todo: biología, física, química, con un gran profesor, estupendo; entonces, como pasa siempre con los profesores estupendos te crea un interés enorme por su materia, en este caso la ciencia. Cuando terminé el bachillerato (la enseñanza media) decidí estudiar ciencias y me fui a física, mi licenciatura es en física en la Universidad 


\section{Francisco J. Ayala: el hombre renacentista de la evolución}

de Madrid y entonces mientras tanto, me interesé cada vez más por la naturaleza de las cosas y por la naturaleza del mundo. Segundo, me di cuenta que muchas de las cuestiones que se planteaban sobre todo en física nuclear subatómica y en astrofísica que me interesaban mucho, eran, hasta cierto punto, cuestiones filosóficas. Entonces decidí estudiar filosofía; para hacer lo equivalente a una especie de doctorado, decidí estudiar puramente filosofía por 3 años. Fue también hacia entonces que me reconvertí al cristianismo que había dejado de practicar.

(Ana) Pero tu familia es muy religiosa.

(FJA) Mucho; mis padres eran muy oficialmente religiosos.

(Ana) O sea, fuiste educado en ir a misa, el rosario....

(FJA) Yo fui hasta antes de la universidad a un colegio de padres escolapios, un colegio católico.

(Ana) De dominicos.

(FJA) No, escolapios. Es una orden que es muy común en España, que se dedica especialmente a la enseñanza. Tuvimos misa todos los días durante muchos años, ya en los últimos años yo ni iba, porque como decíamos entre amigos, habíamos ido ya a misa por toda nuestra vida. En cualquier caso, yo había dejado de practicar y entonces me reconvertí, como digo, al catolicismo. Fue una reconversión entusiasta; como ya tenía estudios avanzados tuve que hacer un año de noviciado, esto era en la orden de los dominicos.

(Ana) Esto en Madrid.

(FJA) La reconversión, por decirlo así, tuvo lugar en Madrid en donde vivía entonces; yo quise entrar a la orden de los dominicos y el primer año era un noviciado en Palencia y después del año de noviciado y de otros estudios más o menos cortos en duración, tuve 5 años de estudios de teología en la Universidad de Salamanca y esos llevaron consigo los títulos al final del Licenciado y un título que los dominicos llaman Lector, equivalente a Doctor que es el que te da la capacidad para enseñar como profesor en una universidad, es un título antiguo antes de que existiera el de doctor.

(Ana) Una vez que terminaste física.

(FJA) Estudie filosofía, interrumpí por un año de noviciado y 5 de teología. Mientras estaba estudiando filosofía, antes de estudiar teología, me había empezado a interesar por la evolución.

(Ana) ¿Cuáles son tus filósofos favoritos o cuál es tu escuela filosófica?

(FJA) Eso son dos fases muy distintas. Durante mi educación de teología y filosofía escolástica me gustaron mucho Aristóteles y Santo Tomás de Aquino. Hacia finales de los 50 y durante la década de los 60 los filósofos que yo leía más y me influyeron más, no lo vas a imaginar 


\section{Ana Barahona Echeverría}

cuáles son: los existencialistas; yo leía mucho, sobre todo durante los años 50, acerca de la filosofía existencialista, que me ha afectado en mi manera de pensar como individuo, mi modo de vida y cómo yo evalúo las relaciones personales, las relaciones sociales.

(Ana) Y dentro de los existencialistas ¿tienes uno favorito?

(FJA) Los existencialistas más conocidos como Heidegger y Paul Sartre, también Gabriel Marcel y Albert Camus y algunos otros alemanes. Los leí mucho y eso influyó mucho mi actitud con respecto a la vida. Más recientemente, empezando los años 70 o finales de los 60 me empieza a influir mucho Karl Popper.

(Ana) ¿Lo conociste personalmente?

(FJA) Si, lo invité a una conferencia en el año 72 en Belaggio y nos hicimos muy amigos y si tú ves mis libros de Popper, las copias que tengo ahí, casi todas están dedicadas personalmente "con mucho cariño». Si tenía una nueva edición de cualquiera de sus libros, me la mandaba siempre.

(Ana) Y además eres popperiano en tu forma de ser.

(FJA) Nos hicimos muy amigos, yo creo que jugué un papel fundamental en su cambio de idea respecto de si la evolución es una hipótesis científica o no. Como resultado de estas conversaciones muy largas que teníamos, él hizo un reconocimiento muy importante cuando la Academia de Ciencias lo eligió miembro extranjero en el área de Ciencias Políticas y Económicas, y en vez de juntarse a esta sección se juntó a la sección de Evolución. Y eso no sólo está en los archivos, sino en algunas cartas de él en donde me lo decía; además lo hizo público, incluyendo una entrevista publicada con el filósofo español Jesús Mosterín en que le pregunta por qué se juntó a la sección de Evolución y no a cualquier otra de la academia y, aunque Mosterín sabía la explicación, Popper respondió «porque ahí estaba Ayala y porque además es una manera de expresar mi cambio de ideas sobre si la evolución es una teoría científica o no". Luego seguimos muy amigos y de hecho la última vez que vino a California, yo quería que viniera aquí a Irvine a hablar, pero no pudo pues ya no estaba muy bien de salud y yo lo fui a visitar a Palo Alto.

(Ana) Decíamos que eres físico de origen.

(FJA) Estudié física y filosofía; eso tiene dos razones, una de ellas es que el estudio de estas cuestiones filosóficas me convenció de que lo que era más interesante era estudiar uno de los problemas más importantes filosóficamente, el origen de la humanidad y de dónde venimos y esto en parte suscitado por lecturas de varios libros, pero muy especialmente por la publicación de los libros de Teilhard de Chardin, el antropaleontólogo jesuita, cuyos libros fueron los más influyentes en estimular mi interés 


\section{Francisco J. Ayala: el hombre renacentista de la evolución}

en la evolución. Su libro más importante nunca se lo dejó publicar la orden de los jesuitas, a la que él pertenecía; él había dejado manuscritos con varios amigos y gente influyente y cuando se murió se los publicaron; aparecieron en el año 55 en francés y poco después se tradujeron al español. El primero de los libros de él lo leí en francés, El fenómeno humano, entonces me entusiasmaron mucho sus ideas y empecé a leer todos sus trabajos y esto contribuyó mucho a que me interesara sobre la evolución y que empezara a leer al mismo tiempo que estaba estudiando teología. Empecé a leer bastante sobre la evolución y descubrí, me acuerdo exactamente el sitio donde lo descubrí, en la ventana de una tienda de libros en Salamanca, Genética y el origen de las especies de Theodosius Dobzhansky. Leí ese, leí también el de Julian Huxley Evolution: The new synthesis en español porque no leía en inglés, no lo sabía bien como para leer libros.

(Ana) Pero francés sí.

1 (FJA) Francés sí, eso lo había aprendido desde niño, lo leía bien, lo hablaba bien; entonces leí el libro de Richard Goldschmidt La base Material de la Evolución, también un libro de Morgan con un título parecido a estos libros y me interesé mucho por la base genética de la evolución. Entonces un amigo de mi familia, un genético de nombre Antonio Zulueta, me empezó a recomendar ciertos libros y también me puso en contacto con Fernando Galán que era un genético que había sido estudiante suyo y que vivía en Salamanca. Fernando Galán quien murió recientemente, había hecho el doctorado en el año 1936, año en el que empezó la guerra civil española, él era muy joven, tenía cerca de 26 años. En esa época no había cátedras de genética en España, al menos en Salamanca; Galán era catedrático de biología. Yo fui a verle en el año 57 o 58, una cosa así, y nos hicimos amigos y justo él acababa de recibir una gran colección de mutantes de Drosophila aunque su investigación era con plantas de Ecballium elaterium. Entonces Galán me dijo, "si tú quieres aprender más sobre genética, por qué no vienes a mi laboratorio, yo tengo estas cepas de Drosophila para hacer prácticas con los estudiantes, pero tú las puedes usar y hacer los estudios que te interesen.» Entonces yo empecé por mi cuenta, con consejo de él. Empecé a manejar moscas y hacer cruzas y de hecho hice mediciones bastante precisas de entrecruzamiento en el cromosoma dos usando muchos marcadores. Durante muchos años después él utilizó mis datos en sus clases, porque decía que en todas partes se encontraban frecuencias de recombinación, pero en ningún libro de texto se daban números. Durante esos trabajos que yo hacía por mi cuenta, encontré varios resultados interesantes, incluyendo un nuevo mutante de Drosophila que después sirvió de tesis doctoral para un estudiante de Galán. Cuando yo 


\section{Ana Barahona Echeverría}

ya terminaba mis estudios de Teología en Salamanca decidí que lo que yo quería estudiar era la evolución general y fueron Galán y Zulueta quienes me recomendaron que lo mejor era estudiar a nivel genético porque es donde se aprenden las causas. Ellos me recomendaron que una de las personas más interesantes para este tipo de estudios era Dobzhansky, aunque yo estaba también interesado en Waddington; a través de estas conversaciones, en algún momento, decidimos que Dobzhansky que estaba en New York, era mucho más interesante para mis propósitos y personalidad. Yo, mientras tanto, había hablado con otras personas, algunos de ellos científicos españoles que vivían en América. Eventualmente, Zulueta le escribió una carta de presentación mía a Dobzhansky. Zulueta había sido posdoc en el laboratorio de Morgan justo cuando Morgan acababa de mudarse de la Universidad de Columbia, N.Y., al Tecnológico de California. Dobzhansky era entonces también posdoc en el laboratorio de Morgan (aunque Dobzhansky no tenía el doctorado propiamente tal, pero había sido profesor por 2 años en la Universidad de San Petersburgo). Así, Dobzhansky y Zulueta se habían conocido relativamente bien porque durante varios meses o un año habían estado trabajando juntos. Zulueta en ese tiempo descubrió que el cromosoma «Y» tenía genes, en contra de lo que se creía hasta entonces de que era genéticamente vacío. Eso era a principios de los años 30 y después cuando él vuelve a España dirige la tesis doctoral de Galán que trabaja con el mismo escarabajito Phitodecta variabilis en el cual Zulueta había hecho la demostración.

Como te decía, Zulueta había hecho la demostración genética de que había genes en el cromosoma "Y", y Galán como tesis doctoral había hecho la demostración cromosómica a nivel citogenético. En cualquier caso, Zulueta le escribe a Dobzhansky quien le dice que le parece que soy una persona interesante y que sí, que venga a trabajar con él, hacemos los trámites no sólo ya para trabajar en su laboratorio sino para realizar estudios de doctorado, pasar la disciplina de las clases y todo eso y ya vine.

(Ana) ¿En qué año llegaste?

(FJA) En el año 1961.

(Ana) Y las publicaciones, tienes un conjunto de publicaciones que ahora entiendo por qué casi todas son de Salamanca, porque ahí estudiabas.

(FJA) Claro y además yo era editor de una revista universitaria en la que escribía editoriales, frecuentemente sobre la evolución.

(Ana) Tienes, además, algunas sobre teología, pero también otras sobre cine.

(FJA) Por cierto, la publicación, y de eso estoy bastante orgulloso «La Persona y la Sociedad Política» es un trabajo interesante, es la primera 


\section{Francisco J. Ayala: el hombre renacentista de la evolución}

publicación un poco erudita que publiqué siendo yo estudiante de filosofía, con sólo unos 20 años de edad. Es un estudio analítico filosófico sobre los derechos del individuo con respecto a la sociedad. Esto me interesaba mucho porque era una manera a nivel intelectual de rebeldía contra la situación política española que era la dictadura. Este artículo arguye en contra de la dictadura de una manera sutil y un tanto escolástica y no explícitamente atacando a Franco pero a su modo de gobierno sí. Eso lo publiqué en el año 54 a más tardar me imagino. Ésa es mi primera publicación, pero durante esos años también yo estaba muy interesado en el cine y entonces una revista de Madrid y un periódico me encargaba que escribiera reseñas de películas y entonces cuando yo estaba en Salamanca establecí un club con unos amigos, un tipo de club dedicado al cine, una cinemateca. No se si este tipo de club existe todavía.

(Ana) En México sí.

(FJA) En México, pero yo estoy hablando de los años 50 en España. Escribí algunos ensayos sobre el cine como forma de arte, que entonces no era tan aceptable, sino que se veía sólo como entretenimiento. El club y los escritos nos servían para explorar problemas serios, psicológicos o de tipo social o lo que sea. Cuando vine a Nueva York, como eso me interesaba mucho lo seguí en parte, era miembro de la «Filmakers Cinemateque», que era un grupo muy avantgarde que entonces no era muy conocido, y en el que conocí a gente como Andy Warhol que era uno de los más activos en este grupo y su expresión artística era por entonces principalmente el film. Sus películas duraban 4 horas, estáticas, muy pop.

(Ana) Estas publicaciones iban hasta el año 60, luego no existe nada publicado por ti hasta el año de 65 , de 61 a 64 supongo que hiciste tus estudios y luego ya en 65 empezaste a publicar.

(FJA) Empecé en el otoño del 61 como estudiante de doctorado en la Universidad de Columbia en Nueva York y terminé en el verano del 64 y a partir de entonces empezaron a aparecer algunos artículos.

(Ana) He visto fotos del grupo de Dobzhansky donde estás tú, apareces todavía vestido de sacerdote. ¿Cuándo abandonaste los hábitos?

(FJA) En el 67; yo me ponía ese uniforme de sacerdote para las fotografías más o menos oficiales.

(Ana) $\mathrm{Y}$ en el año de 67 decidiste colgarlo para siempre.

(FJA) Ya, dejé no tanto el sacerdocio como la iglesia, dejé de ser practicante católico. Me sigo llevando bien con mis compañeros de entonces y a veces oficialmente, incluyendo a los obispos, me invitan a que dé conferencias o escriba en revistas católicas.

(Ana) ¿Cuándo dejaste de pensar que ibas a regresar a España, cuándo fue claro que te ibas a quedar en Estados Unidos? 


\section{Ana Barahona Echeverría}

(FJA) Aproximadamente y de manera gradual entre el año 1965 y 1967. Empecé a explorar la posibilidad cuando terminaba mi año posdoctoral en 1965. Dobzhansky trataba de convercerme de ello, siguió influyéndome y gradualmente durante el año y medio siguiente o algo así, me convenció totalmente de que yo debería quedarme.

(Ana) Quedarte por más tiempo o ya para siempre.

(FJA) Indefinidamente, que no es lo mismo que para siempre, quiere decir que es abierto. Entonces en el verano de 1967 solicité la residencia y acepté un puesto que me ofrecían de profesor asistente en Rockefeller University.

(Ana) Y el año siguiente fue cuanto te casaste, en 1968.

(FJA) Mientras tanto en ese mismo tiempo yo también había decidido dejar la iglesia, el sacerdocio y entonces a fines de mayo del 68 me casé.

(Ana) Y luego vinieron los hijos muy pronto.

(FJA) En marzo del 69 el primer hijo y dos años nueve meses más tarde el segundo.

(Ana) ¿Y cuándo te nacionalizaste norteamericano?

(FJA) En 1971, que quiere decir que yo debía de haber solicitando la «green card» no en el 67 sino en el 66 porque se requerían cinco años de residencia.

(Ana) Y ya en ese momento estás convencido de ser ciudadano americano, para poder quedarte.

(FJA) No, porque para poder quedarte con la tarjeta verde te puedes quedar para toda la eternidad como lo hace mucha gente. La razón para hacerse ciudadano americano no es el quedarse más o menos tiempo, porque si uno tiene la tarjeta verde, uno se puede quedar indefinidamente y, de hecho, mucha gente lo hace así por toda su vida, y nunca se hacen ciudadanos. A mí me parece que una vez que mi intención era ya quedarme aquí pasando de «indefinidamente» a "probablemente para siempre» entre 66 y 71, que lo mejor era hacerme ciudadano americano porque era la única manera de participar de manera completa en la vida pública y social, y además, una de las razones por las que yo decidí quedarme aquí o que me influyó a quedarme aquí primero «indefinidamente» y después «definitivamente» era mi antagonismo hacia el gobierno español (franquismo) y entonces una vez que decidí quedarme aquí quería romper todos los lazos con el gobierno español de entonces.

(Ana) Y tú crees que si hubieras regresado a España como lo tenías pensado originalmente, de venir, hacer tú doctorado y luego volverte, ¿tu escenario hubiera cambiado mucho como científico?

(FJA) Probablemente. Pero evidentemente hubiera podido regresar a España pero nunca se planteó la cuestión concreta de cómo y dónde, pero 
hubiera podido regresar a Madrid, o a Salamanca y haber encontrado un puesto probablemente de posdoctorado, luego de profesor asistente y ahí se habría formado una carrera en España. Yo creo que esa posibilidad sí existía, pero en cualquier caso, los medios en España en ese entonces para la investigación eran mucho más limitados que en Estados Unidos y muy importantemente entonces y hasta cierto punto todavía, el contexto intelectual en España, el mundo científico, era mucho más limitado; el contexto de los científicos con los que uno trabaja es muy importante porque el estímulo de lo que uno investiga o no, viene también en parte de las conversaciones que uno tiene con otros científicos, la interacción con otras personas, saber lo que están haciendo y esta posibilidad en España, era muy limitada entonces.

(Ana) Y cuando tomaste la decisión de quedarte de forma permanente supongo que también contó en algo que tenías una familia e hijos americanos.

(FJA) La decisión de quedarme aquí indefinidamente antecede a mi matrimonio por lo menos dos años y entonces ya así lo natural también era crear una familia y tener hijos.

(Ana) Esta decisión está conectada por lo menos temporalmente con tú decisión de dejar la iglesia ¿son conexiones causales o simplemente aleatorias?

(FJA) Ambas son sucesos relacionados uno con otro no de manera casual sino de una manera causal, aunque qué es causa y qué es efecto, es una cuestión distinta. Yo podía haberme quedado aquí permanentemente, de hecho la Universidad Rockefeller me había hecho una oferta a través de Dobzhansky para quedarme permanentemente y ser profesor asistente como sacerdote que es lo que ellos creían que yo quería, o sea yo me hubiera podido quedar como sacerdote. La decisión de quedarme en Estados Unidos, por lo tanto, no está ligada necesariamente a dejar los hábitos; una vez que dejé los hábitos era evidentemente también más conveniente quedarse en América que ir a España donde hubiera podido crear problemas en esos años, pero esa no fue la razón por la que me quedé. Ambas están conectadas evidentemente, no es que una posibilidad determinara la otra, pero sin embargo sí están conectadas, las dos se desarrollan de manera psicológica y emocional más o menos al mismo tiempo.

(Ana) Y por ejemplo hablando de esto de la iglesia, ¿fue un proceso muy largo convencerte de dejar la iglesia?

(FJA) De hecho la idea de dejar la iglesia empieza a ser considerada por mí ya un poco antes de venir a Estados Unidos. Ya para entonces estaba de acuerdo con mis superiores que al venir a Estados Unidos a estudiar, los años de estudio iban a ser mi interregno durante el cual yo iba a 
mantener los requisitos oficiales de la vida de sacerdote pero durante los cuales mi mente no estaba segura de que yo podía aceptar todas las creencias católicas. En mi caso, las dificultades con la iglesia católica provienen o tienen origen intelectual y de hecho, están asociadas en parte creo yo, con mi entusiasmo, por así decirlo, con el existencialismo (eso a través de mis estudios de existencialismo). Yo me convenzo de que la vida tiene significado en sí misma, que no hay que buscar significados últimos más haya de la experiencia vital directa del individuo. Por eso te decía que estaba relacionada causalmente: yo ya estaba pensando en la posibilidad de dejar en el año 1960 la iglesia por razones intelectuales, pero me puse de acuerdo con de mis superiores de que iba a seguir como sacerdote por tres o cuatro años. Yo no tenía ninguna prisa en dejar oficialmente la iglesia, mientras, yo seguía explorando estas alternativas de mi vida.

(Ana) El hecho de que fueras a ser sacerdote o hayas estudiado el sacerdocio, ¿fue una cosa impuesta en la familia o fue una decisión tuya?

(FJA) No, la respuesta es al contrario, mis padres se desilusionaron mucho, yo les sorprendí muchísimo cuando decidí que iba a estudiar para ser monje.

(Ana) Tú no eres el menor de tus hermanos.

(FJA) De los hombres si, de la familia no.

(Ana) Tú decides continuar con la carrera de sacerdote antes de venir a Estados Unidos y aquí definitivamente te convences.

(FJA) Gradualmente me convenzo sí, pero ya había considerado la posibilidad de deja la iglesia y tenía también este acuerdo de que iba a permanecer 3 ó 5 años más dentro de ella, al menos «oficialmente».

(Ana) ¿A qué grado influyeron tus creencias sobre la evolución?

(FJA) No, en absoluto.

(Ana) Tú influencia fue más de tipo filosófico.

(FJA) Mucho más, particularmente la filosofía existencialista acerca del significado de la vida.

(Ana) Se puede ser evolucionista y ser creyente, tú eres creyente.

(FJA) Depende de que quieres decir por creyente, no soy católico, no acepto los dogmas fundamentales de la iglesia católica.

(Ana) Pero crees en Dios, así como Huxley que según él no era católico pero...

(FJA) Es un problema distinto que yo normalmente no contesto directamente por razones que tienen que ver con las controversias de los creacionistas porque no quiero que me puedan citar y decir «este señor claro, es un ateo por eso testifica aquí». Yo tomo la posición de lo que tú decías antes, se puede ser creyente y se puede ser evolucionista y de que si yo soy creyente o no es totalmente irrelevante para ese asunto; cuan- 
do la gente me pregunta si creo en Dios o no, la manera de evadir la respuesta es decir «qué quieres decir con Dios, como defines a Dios» y eso es un problema que se puede perseguir indefinidamente y al final nunca se resuelve la cuestión.

(Ana) Creo que tú tienes un carácter en el sentido de que tomas una decisión de tajo.

(FJA) Que no quiere decir que no puedas cambiar luego, pero normalmente ya no quedan más dudas.

(Ana) Y cuando decidiste dejar los hábitos, tuviste que ir a España para hablar con tus superiores o les escribiste una carta, ¿cómo fue tu renuncia?

(FJA) Como yo dejaba la iglesia no había razón para, por ejemplo, ser dispensado de los votos de sacerdocio (cosa que necesitas hacer si quieres seguir practicando como católico). Me comuniqué con ciertos superiores por carta en donde les explicaba, y hablé personalmente con otros aquí en Estados Unidos; lo mismo hice con mi familia. Me ofrecieron la oportunidad de dispensarme de los votos del sacerdocio pero les dije claramente a mis superiores, "si os hace sentiros bien a vosotros lo hago, pero a mi no me significa nada.» Dadas las circunstancias estuvieron de acuerdo conmigo de que no valía la pena el papeleo.

(Ana) Cuando llegaste a Estados Unidos, a Nueva York, tú vivías solo, siempre has sido muy autónomo.

(FJA) Yo vivía por mi cuenta y prefería así porque además yo llevo una vida que podría ser difícil para otra persona.

(Ana) En qué sentido.

(FJA) Duermo muy poco, me acuesto a media noche, me gusta levantarme a las 4 o 5 de la mañana, empezar a leer, trabajar o ducharme, lo que sea, entonces para otra persona es muy desagradable, además es preferible tener autonomía.

(Ana) ¿Siempre te has levantado a esa hora?

(FJA) Si, desde que tengo 18 o 20 años me despierto muy temprano, me eduqué a mí mismo a dormir poco. A otro nivel soy muy sociable con todo tipo de gente, y así hice amigos con los estudiantes de Columbia, y con otros, con hombres y mujeres, aunque yo no salía con chicas, porque era sacerdote de nombre. Éramos simplemente amigos y no había otro tipo de relación, hasta que dejé el sacerdocio, entonces sí.

(Ana) Y una vez que estabas estudiando el doctorado ¿cuáles eran tus principales campos de investigación? porque así la evolución me suena muy general, muy amplio.

(FJA) Yo estaba interesado en la genética porque era una manera de estudiar las causas de la evolución, pero sobre todo para aplicarlo al fi- 
nal a la evolución humana y al origen del hombre. Entonces, en el primer año de estudiante graduado había un curso de genética que duraba todo el año. El primer semestre era genética general y del desarrollo y el segundo era principalmente genética evolutiva y genética de poblaciones, pero coincidiendo con el segundo semestre había un semestre de laboratorio en donde había que hacer un experimento y Dobzhansky acababa de volver de un año sabático y había traído de Australia y de Nueva Guinea varias nuevas estirpes de Drosophila de la especie serrata. Me acuerdo de cuando él nos habló al comenzar el laboratorio y nos dijo, entre otras cosas, que sería muy interesante estudiar estas estirpes y saber las relaciones entre ellas. Entonces yo, como práctica de laboratorio, además de alguna otra cosa que tenía que hacer en general, pero como proyecto para ese semestre, decidí estudiar esas estirpes y entonces descubrí que había por lo menos 3 especies distintas, a una de ellas la llamé Drosophila birchi y de esa dije que había 3 subespecies. Aunque no las nombré, una era de Australia, otra de Nueva Guinea y la otra de otras Islas; Drosophila serrata estaba menos diferenciada, en Nueva Guinea se encontraba como la misma especie que en Australia. Después descubrí una tercera especie que la llamé Drosophila dominicana en honor de los dominicos. Drosophila birchi está nombrada en honor a L. C. Birch que es un ecólogo muy famoso que escribió un libro con H. B. Andrewartha The Distribution and Abundance of Animals. Él había sido el anfitrión por así decirlo de Dobzhansky durante su visita en Australia y también en esa época nos había visitado; Birch y yo nos hicimos amigos pues él estaba interesado también en cuestiones filosóficas y religiosas.

(Ana) tú describiste birchi y dominicana.

(FJA) El primer trabajo lo publiqué en Evolution, mostrando que hay 3 grupos aislados reproductivamente, que producen híbridos estériles. Lo escribí el primer año de estudiante de doctorado, pero decidí empezar otro proyecto para mi tesis doctoral. Para la tesis doctoral, había que escribir como pre-requisito una monografía durante el $2^{\circ}$ y $3 \mathrm{er}$ año sobre algún tema, ese era uno de los requisitos del departamento de Columbia, entonces yo decidí escribir sobre los conceptos de "fitness" o adecuación porque veía contradicciones entre la fitness darwiniana que es una medida relativa, y la fitness en el sentido común de bienestar y adaptación. Yo escribí sobre ese asunto y entonces decidí hacer mi tesis doctoral sobre eso tratando de encontrar una medida o una entre posiblemente muchas, que pudiera servirme para medir la fitness en un sentido más común, pero para una población, no para el individuo. Mi tesis doctoral está dedicada a ese problema que es un problema en el que Dobzhansky no había tenido interés sino hasta entonces, ciertamente no había hecho estudios experimentales, por- 
que era una manera nueva de ver las cosas y entonces él sugirió o yo lo propuse tal vez. Yo tenía interés de terminar lo más pronto posible para volver a España y entonces quería hacerlo rápido. Dobzhansky sugirió que si los resultados de los estudios de fitness no los tenía terminados al final de mi tercer año de estudios, podría usar el descubrimiento de las nuevas especies australianas como tesis doctoral y terminar lo otro más tarde.

(Ana) En España se suponía.

(FJA) Si en España que era a donde quería volver. Entonces resulta que para el fin del $2^{\circ}$ año yo ya había terminado con todos los cursos requeridos y la tesis, pero no me podían dar el doctorado porque Columbia University requería tres años mínimos de residencia. No se me ocurrió que podía pedir una excepción.

(Ana) Estamos hablando de 1964.

(FJA) Bueno yo ya había terminado con todos los requisitos en 63 . Según el trabajo de la tesis doctoral durante 64 porque no podía recibirme. Mientras tanto aparecieron otros trabajos laterales en Genetics, Evolution, Science, Ecology, American Naturalist, algunos otros en Pacific Entomology sobre la descripción de especies, no está mal para 3 años.

(Ana) No, no está mal.

(FJA) Entonces cuando yo terminé, Dobzhansky dijo que era mala idea que yo regresara a España, porque no iba a tener las oportunidades para hacer este tipo de investigación, parece que yo lo estaba haciendo muy bien, entonces me invitó a ir de posdoc a la Universidad Rockefeller, (él se había cambiado de la Universidad de Columbia a la Universidad Rockefeller), y fui ahí un año, del 64 al 65.

(Ana) Entonces tus planes eran terminar el doctorado y regresarte a España.

(FJA) Entonces Dobzhansky me dijo "quédate al menos un año" y Dobzhansky era muy ruso y creía en el lavado de cerebro sistemáticamente. Claro, evidentemente tuvo éxito. Durante ese año de posdoc quise comprobar una idea que había tenido y que era el centro de la tesis de doctorado: cómo medir la fitness en las poblaciones, cuál es el papel que ha jugado la variabilidad. Aumentando la variación genética aumenta la fitness. Entonces diseñé un experimento con un sistema de radiaciones; consiste en aumentar la variación por radiación, pero con un sistema de filtro. Las mutaciones malas se eliminaban inmediatamente, entonces esto daba oportunidad a las demás a que persistieran sin competencia durante bastante tiempo. En ese año también empezaba a venir, principalmente de un grupo de Texas, la idea de que uno podía medir la variación genética directamente por medio de enzimas, electroforesis de enzimas y entonces empecé a usar estos métodos. 
(Ana) Te refieres al grupo de Stone en Texas.

(FJA) Exactamente, Stone y Harris fueron los que empezaron a hacer electroforesis con enzimas desde el punto de vista de genética de poblaciones. En cualquier caso yo empecé a introducir en el laboratorio de Dobzhansky estos métodos. Al principio Dobzhansky era muy escéptico, porque no creía mucho en la química aunque sí hacia mucha citología y citogenética, pero un año o 2 más tarde, ya estaba completamente convencido de su importancia. Cuando yo volví a la Rockefeller en el año 67 ya como profesor asistente, entonces montamos un laboratorio a toda regla para hacer investigaciones de electroforesis de enzimas, bueno lo voy a dejar ahí y tú haces la próxima pregunta.

(Ana) En el año de 1967 aparece tu primera publicación con Drosophila pseudoobscura, de aquí en adelante tu trabajo principalmente de genética de poblaciones es con Drosophila pseudoobscura y algunos otros trabajos con melanogaster.

(FJA) No, hay alguno con Drosophila pseudoobscura, y alguno con melanogaster, pero mis publicaciones sobre variación enzimática fueron al principio con especies del grupo willistoni, que había sido estudiado por Dobzhansky y muchos sudamericanos. Este grupo tiene una especiación muy activa, con muchas especies incipientes. Entonces empecé a estudiar varios problemas, incluyendo el de tratar de averiguar la cantidad de variación genética a nivel poblacional entre poblaciones, que entonces no se sabía, y que era una cuestión básica. Los primeros datos que aparecen eran del grupo de Stone junto con estudios sobre pseudoobscura y persimilis por Hubby y Lewontin. Yo quería hacer estudios semejantes con el grupo willistoni, primero porque consiste de varias especies y quería estudiar una especie, después otra, otra y otra y ver si los patrones que se observaban en una especie se confirmaban en otra en el sentido de testing o corroboración. La distribución de las especies del grupo willistoni es muy amplia, va de México hasta Brasil y Argentina y gracias a esto se podría estudiar una gran extensión geográfica incluyendo, y esto me parecía muy atrayente, islas del Caribe, tanto las pequeñas como las grandes (Puerto Rico, Hispaniola, Jamaica, etc.). Uno de mis objetivos era investigar la relación entre la variación y el tamaño de la población. Uno de los proyectos que llevé a cabo durante esos años era el de tratar de medir la cantidad de diferenciación genética que acompaña al proceso de especiación. El grupo willistoni era particularmente favorable porque había varios estadios desde poblaciones esparcidas geográficamente hasta subespecies, especies incipientes, semiespecies, después especies gemelas, especies no gemelas, etc., yo quería ver cómo la diferenciación genética aumentaba en consonancia con el aislamiento reproductivo. Varios de los trabajos más impor- 


\section{Francisco J. Ayala: el hombre renacentista de la evolución}

tantes que yo escribí en esos años tienen que ver con el problema de la especiación, mientras que al mismo tiempo otras publicaciones tienen que ver con el problema más general de la variación genética.

(Ana) ¿Y tú crees que estas preguntas que te hacías en esa época eran preguntas clásicas de la genética de poblaciones, la medición de la variabilidad genética, qué tanta variación había en la naturaleza, cuál era el número efectivo de una población?

(FJA) Eso sí, pero ahora se podrían investigar de nuevas maneras; lo que no se podía investigar antes de ninguna manera razonable y ahora sí, es el problema de la diferenciación genética durante el proceso de especiación, un problema nuevo, porque antes no había manera de investigar ese problema.

(Ana) Y tú ¿cómo lo estudiaste?

(FJA) Comparando las poblaciones en dos distintos estadios de especiación, primero comparas poblaciones geográficas distintas, en el paso siguiente se colocan poblaciones en las que haya aislamiento reproductivo incipiente.

(Ana) En la actualidad esto se estudia usando electroforesis, con una proteína particular.

(FJA) Lo importante es usar una muestra grande, digamos 30 ó 36 genes distintos para obtener un valor medio, lo esencial es estudiar muchos genes para hacer estimados cuantitativos de la diferenciación.

(Ana) Y entonces tú dices que esta parte, las técnicas de electroforesis, las introdujiste tú en el laboratorio de Dobzhansky.

(FJA) Todo el trabajo de electroforesis lo introduje yo. Dobzhansky decía que si él fuera más joven aprendería esas técnicas, pero era muy mayor para aprender técnicas nuevas; pero eso lo introduje yo; además lo enseñaba a gente que empezaba a venir y que trabajaba conmigo ó gente que fueron nominalmente sus estudiantes de doctorado (en esa época en Rockefeller sólo los profesores tenían estudiantes, sus asistentes no) como Rollin $\mathrm{C}$. Richmond y después, un año o dos más tarde Jeffrey R. Powell, quien de hecho terminó el doctorado en Davis, California, aunque lo había empezado en Rockefeller.

(Ana) Estábamos hablando de los problemas clásicos de la genética de poblaciones, en esa época tus primeras publicaciones conjuntas con otras personas aparecen en el año de 69, con S. Pérez Salas, R. C. Richmond de quien hablabas hace un momento y con C.A. Mourão, con Dobzhansky tú primer artículo es hasta el año de 70. Hasta este momento eres el único autor.

(FJA) Con Dobzhansky hay dos tipos de trabajos que yo me acuerdo. Uno de ellos es un proyecto que decidimos empezar cuando todavía esta- 
bamos en Rockefeller en 67, de ver si había asociaciones sistemáticas entre los patrones de cambio de frecuencia temporal de los cromosomas con las estaciones. Queríamos averiguar si lo que él había descubierto hacía muchos años, es decir, que las secuencias de ciertos cromosomas cambiaban con las estaciones, si las enzimas hacían lo mismo, las enzimas que estaban dentro y fuera de los cromosomas y este proyecto daba además la excusa de venir en el verano a California, a Sierra Nevada y colectar moscas y demás.

(Ana) $¿$ Te refieres a «Enzyme variability in the Drosophila Willistoni group I.» Con Ayala, Mourão, Pérez Salas, Richmond y Dobzhansky, que apareció en 1970 en los Procedings of the National Academy of Sciences, (PNAS)?

(FJA) No, me refiero a una publicación en PNAS en que Dobzhansky y yo somos los únicos autores sobre la variación estacional de Drosophila pseudoobscura. Este trabajo lo empezamos a publicar en PNAS y luego en algunas otras revistas.

El trabajo a que tú te refieres es con Drosophila willistoni, especie sudamericana. Añadimos a Dobzhansky como autor porque él tenía muchas de las colecciones que habíamos usado. Mourão que es un brasileño, y Pérez Salas que es un venezolano, estaban de posdocs en el laboratorio de Dobzhansky aprendiendo esas técnicas conmigo. Richmond era un estudiante que acababa de llegar también a Rockefeller e hizo su tesis doctoral sobre uno de estos problemas de variación en Drosophila paulistorum, una especie particular del grupo willistoni. Otro trabajo que probablemente publicamos por entonces, hacia 1971, consistió en que Dobzhansky y yo resumimos toda la información que existía sobre distribución geográfica, sobre enzimas, y sobre los conocimientos que se sabían de aislamiento reproductivo, variación de cromosomas, y partes ecológicas sobre todas las especies del grupo willistoni. El artículo lo publicamos en Evolution, y resume muchos de los conocimientos en el grupo willistoni que estaban esparcidos en muchos artículos. Pusimos ahí a toda la gente que en algún momento, habían trabajado con el grupo willistoni. Por supuesto tiene como 15 ó 20 autores.

(Ana) En 73 y 74 hay una descripción de una nueva subespecie de Drosophila pseudoobscura con Dobzhansky y luego tienes dos libros uno con Dobzhansky, Estudios en filosofía de la Biología y otro Evolution con Dobzhansky, Stebbins y Valentine; posteriormente una conferencia que se publicó sobre la evolución de la humanidad.

(FJA) Esta última era una conferencia que él iba a dar, lo dije en la introducción a la publicación, él iba a dar esa conferencia en Sudáfrica para celebrar el 50 aniversario, una cosa así, del descubrimiento del pri- 


\section{Francisco J. Ayala: el hombre renacentista de la evolución}

mer Australopithecus por Dart y Tobias, entonces Dobzhansky estaba escribiendo esa conferencia hasta el día que murió. Durante varios meses escribía este tipo de trabajos en casa, por la tarde, un ratito media página, una página, a veces trabajaba él otras cosas pero escribía un poco todos los días, yo iba a su casa después de cenar y lo encontraba escribiendo, y cuando murió la conferencia estaba a un poco menos de la mitad de terminar.

(Ana) ¿En que año murió?

(FJA) Diciembre de 75. Cuando Tobías se enteró (él era amigo de Dobzhansky) que él ya había muerto, pero que había estado trabajando en la conferencia en los días previos, me dijo "porque no la completas tú" y yo la completé tratando de reflejar más bien las ideas de Dobzhansky en vez de las mías. La conferencia se publicó en 1977 con el título de «The Evolutionary Transcendence of Humankind».

(Ana) Y regresando un poco a tú relación con Dobzhansky. Llama mucho la atención que tengas muy pocos trabajos publicados con él. Esto se debió en parte a que las preguntas que ustedes dos querían resolver eran completamente diferentes, tú hiciste que Dobzhansky se interesara en el tipo de problemas más básico de la genética de poblaciones, como la variabilidad enzimática, ¿es eso correcto?

(FJA) Es correcto, desde el principio empecé a interesarme por mis propios problemas. Dobzhansky no trataba de que la gente trabajara en lo que él quería; solo cuando la gente no sabía que hacer, entonces él les proveía problemas. Yo sigo la misma práctica. Si alguien viene a mi laboratorio y tiene sus propias ideas, como por ejemplo Michel Tyberanc, un francés que vino en el año 85 explícitamente para trabajar en Trypanosoma, y consiguió que yo me interesara en esos problemas. Lo mismo era con Dobzhansky. Yo tenía mi propia problemática. La conferencia sobre filosofía de la ciencia fue en 1972 y fue una cosa que se me ocurrió a mi organizarla, con su bendición y con la ventaja de utilizar su nombre y su fama al invitar a los participantes. Los trabajos se publicaron con el título Studies in the Philosophy of Biology, del que hablábamos antes, en 1974. Por cierto que yo le llevaba a Dobzhansky todas las cosas administrativas del laboratorio desde que llegue a la Universidad Rockefeller en el año 67, como profesor asistente. Lo discutíamos todo, lo hablábamos todo, incluyendo los proyectos de investigación para los visitantes y cosas así, estábamos muy cercanos también personalmente, sobre todo porque le gustaba hablar de problemas filosóficos y no tenía con quien hablar y los posdoc estaban interesados en la ciencia y no la filosofía, entonces hablábamos de esas cosas. Teníamos amistades conjuntas que no eran ya directamente del laboratorio. Ahora que me acuerdo, organicé también 


\section{Ana Barahona Echeverría}

un programa muy interesante sobre los aspectos y las implicaciones morales de la ingeniería genética, una serie de seminarios en el año 67 en la Universidad Rockefeller. En 67 y 68 la ingeniería genética no existía, ni mucho menos, pero ya se anticipaban los problemas, entonces conseguí la participación de Dobzhansky y varios otros profesores famosos como Edward Tatum y E. Dubois. Nos reuníamos cada dos semanas y discutíamos estos problemas, aunque nunca llegamos a publicar nada, pero tuvieron mucha influencia en convencer a varios genéticos y biólogos moleculares famosos y darles conciencia de las dimensiones éticas de estos problemas que algunos de ellos no creían que debía haberla, aunque eventualmente se convencieron.

(Ana) Problemas que ahora están volviendo un poco a ser elaborados con el proyecto del genoma humano.

(FJA) Exactamente, 25 ó 30 años más tarde.

(Ana) ¿Existen estos seminarios publicados?

(FJA) No, de hecho nos pusimos de acuerdo, éramos solo 10 ó 12 personas y nos pusimos de acuerdo que no, que eran completamente ideas para discutir en privado, para que la gente hablara con libertad. La historia fácilmente se hace muy larga pero ahí había dos o tres participantes que más tarde, cuando se plantean estos problemas de la ingeniería genética como posibilidad práctica inmediata, se convirtieron entre los más activos en enfatizar las responsabilidades morales. Cuando yo empecé esos seminarios me acuerdo que un colega me dijo (él era profesor en Rockefeller y yo era un asistente) «qué problemas éticos ni que cuernos de qué, mira en ciencia lo que se puede hacer cuando se puede hacer se va a hacer, la pregunta si se debe hacer es irrelevante». Suena como una barbaridad y era una barbaridad en ese entonces también, pero a él no le parecía una barbaridad y sin embargo 10 años más tarde cuando ya la ingeniería genética fue posible técnicamente, entonces él se convierte en uno de los firmantes, en una de las fuerzas, de los primeros motores por decirlo así, de la idea de Asilomar y de que sí hay que controlar este tipo de investigación, regularlo y demás. La conferencia de filosofía del año 1972 era distinta, era sobre el problema del reduccionismo, aunque el libro tiene un título más general. El problema del reduccionismo es hasta qué punto se puede reducir toda la biología a la biología molecular como muchos biólogos proponían. Por cierto que en mayo de 1968 Dobzhansky fue el padrino de mi boda. Me acuerdo también de que el día $1^{\circ}$ de junio fue para un chequeo médico y es cuando le descubrieron que tenía leucemia. Ya para entonces como resultado de nuestra asociación en Rockefeller nuestra amistad había sido muy estrecha, él me lo dijo inmediatamente a mi, se lo dijo a su esposa, y a otra persona, pero no lo dio 


\section{Francisco J. Ayala: el hombre renacentista de la evolución}

a conocer en general. Una razón de decírmelo a mí es que él tenía en ese momento la intención de preparar la cuarta edición de Genetics and the Origin of Species y como seguramente, decía él, no iba a tener tiempo de terminarla, me dijo «si yo no lo termino la terminas tú». El libro lo terminó y lo publicó como Genetics of the Evolutionary Process porque cuando terminó el libro (tardó un año y medio en escribirlo) había evolucionado tanto que decidió que necesitaba otro título. En lugar de llamarlo cuarta edición del libro anterior le puso otro título. Volviendo un poco a nuestra mudanza a Davis. Dobzhansky sabía que tenía leucemia y que no iba a vivir mucho, entonces él se jubiló en el año 70 y quiso que yo me quedara con él en la Universidad Rockefeller. Yo no quería quedarme en Nueva York porque ya mi primer hijo había nacido y queríamos tener un hijo más y yo pensaba que para criar niños Nueva York no era un sitio ideal, sobre todo donde vivíamos nosotros. Yo quería mudarme pero le dije a Dobzhansky que no me iría a ningún otro sitio a no ser que fuera en acuerdo con él. Me ofrecieron entonces puestos en varios sitios como Florida, Davis, Berkeley. Entonces acepté ir a Davis, porque tenía un clima estupendo y un gran grupo de genética de poblaciones y de evolución. Cuando estaba negociando mi nombramiento, ya en las fases finales dije que sí aceptaba pero con la condición de que invitaran también a Dobzhansky. Naturalmente se entusiasmaron porque Dobzhansky ni siquiera quería sueldo, nada más quería un laboratorio para seguir trabajando, aunque a mí me dijeron que le preguntara a él que sueldo quería. Entonces yo negocié su laboratorio y su mudanza, como negociaba todo para él, yo me ocupaba de todas las cuestiones prácticas. Yo escribía sus grants y llevé todos los asuntos que implicaban el manejo en el laboratorio desde el año de 67 en que vine de profesor asistente; me ocupaba de todos los asuntos administrativos.

(Ana) Y tú asociación con James Valentine con el que sí publicaste en extenso, casi una veintena de artículos por un espacio que va de 1973 a 1979, él era profesor del Departamento de Geología en Davis.

(FJA) Él era profesor de Geología, entonces nuestra amistad comienza poco después de mi llegada a Davis, en 1971. Creo que dictamos algún curso graduado juntos pero creo que nuestra relación comienza antes que eso. El interés de colaborar científicamente emana de que con las nuevas técnicas se podían resolver problemas clásicos de paleontología; por ejemplo, a él le había interesado siempre el problema del ordenamiento de la diversidad de especies, sobre todo las causas de las extinciones. Por ejemplo, una de las teorías que publicaron por aquel entonces en el año 70 o algo así, dos paleontólogos de la State University of New York en Stony Brook, propone que la razón de las extinciones masivas que apa- 
recen en el registro fósil se debe a que la estabilidad del ambiente durante mucho tiempo, había reducido la variación genética de muchas especies. Cuando el ambiente cambia, las especies no tienen la flexibilidad de adaptarse y entonces se le ocurre a Valentine hablando conmigo investigar este problema con las técnicas de electroforesis que yo estaba usando para medir la variabilidad genética. Cuando hablamos a mí me parecía un problema muy interesante siempre que tuviéramos las muestras apropiadas; entonces la idea fue buscar organismos que vivieran en condiciones aparentemente muy estables y de hecho los proponentes de la teoría habían identificado Tridacna máxima, almejas grandes que viven en los arrecifes de coral, como un ejemplo de los tipos de organismos que deberían tener mucho tiempo adaptándose a estos ambientes y que debían de haber perdido su variabilidad; las colectamos en los trópicos del Pacífico, (al final yo no participé en la parte entretenida de hacer las colectas por falta de tiempo). Resultó que es justo al revés, Tridacna maxima resulta ser el organismo con más variabilidad genética que se conocía en ese momento. Entonces Valentine y yo empezamos a distinguir entre estabilidad espacial y estabilidad temporal, en la teoría original estos dos conceptos estaban un poco confundidos, (estabilidad espacial que es uniformidad y estabilidad temporal que es estabilidad propiamente tal) y empezamos a investigar el problema ya en más detalle buscando organismos apropiados. Hicimos un viaje juntos para colectar especies del fondo del mar, porque ahí si que hay un ambiente muy estable; queríamos también resolver si el gran polimorfismo de Tridacna es cuestión de estabilidad o de abundancia (pues es una especie abundantísima) pues Tridacna vive en un entorno con gran abundancia de recursos; entonces rastreamos el fondo del mar, donde hay gran limitación de recursos, pero gran estabilidad, y encontramos mucha variabilidad. Tratando de resolver la cuestión de qué condiciones del entorno impactaron la variabilidad genética, decidimos estudiar Euphasia superba, un camarón pequeñito, una gambita, pero probablemente la especie numéricamente más abundante del mundo. Tiene un ambiente con ciclos estacionales muy fuertes y con recursos no necesariamente muy escasos. En contraste, el fondo del mar tiene estabilidad, pero pobreza de recursos. Encontramos poca variabilidad en Euphasia. Para resolver la cuestión de si esto era debido a su historia filogenética, o si se rélacionaba con la abundancia de recursos, estudiamos otras dos especies de Euphasia, una de los trópicos y otra de zonas templadas. Así llegamos a los estadios más avanzados tratando de desintegrar las variables que afectan la variabilidad. Al final nos convencimos de que lo que cuenta no es la riqueza de recursos, sino la uniformidad espacial, es lo que hace posible la variabili- 
dad genética porque permite la especialización de genes, esa es nuestra teoría. En el proceso de hacer estos estudios Valentine y yo publicamos juntos bastantes trabajos. Hacia ese tiempo, Dobzhansky, Stebbins y yo decidimos escribir un libro de texto sobre la evolución y pensado originalmente que la parte de paleontología la podría haber hecho Simpson. Yo les propuse a que era mejor escoger a Valentine que estaba allí mismo en Davis, como nosotros tres, y que además tenía ideas nuevas sobre la paleontología. Este libro se publicó con el nombre de Evolution en 1977 por Dobzhansky, Ayala, Stebbins y Valentine.

(Ana) El otro libro muy famoso es Genética Moderna de Ayala y John Kiger publicado por primera vez en inglés en 1984, es un libro de texto sobre genética.

(FJA) Yo con John nunca investigué problemas científicos. El libro se deriva de un curso con varios cientos de estudiantes que Kiger y yo enseñamos juntos durante varios años.

(Ana) ¿Fue tu alumno?

(FJA) No, no, él era profesor asistente en nuestro Departamento de Genética. Su especialidad es la genética del desarrollo.

(Ana) Y de ahí decidieron escribir.

(FJA) Él enseñaba la parte molecular y del desarrollo, y yo daba la parte de genética de poblaciones y de evolución. Yo tenía la idea desde mucho tiempo atrás de que la enseñanza de la genética se podía organizar lógicamente. Algunos libros estaban organizados históricamente, otros los organizaban en términos de complejidad, desde lo más sencillo hasta lo más complejo, y a mi me pareció que se podía organizar la genética con arreglo a las tres funciones principales del material genético que son la transmisión, el controlar el desarrollo del individuo y el controlar la evolución, y es como está organizado nuestro libro en tres partes y ese fue un ejercicio de tratar de enseñar la genética de otro modo.

(Ana) Avise fue tu colaborador, ¿fué tu estudiante también?

(FJA) Estudiante de doctorado.

(Ana) ¿También Gilpin y Muller?

(FJA) Larry Muller fue estudiante mío de doctorado, y por cierto, está aquí en Irvine de profesor. Lo de Michael Gilpin es una historia muy interesante, porque se cierra un círculo que envuelve también a Irvine. Cuando yo estaba todavía en Rockefeller en el año 69 ó 70 un profesor que acababa de llegar a Irvine, me invitó a dar una conferencia. Su nombre es George Hunt y está todavía de profesor aquí en Irvine. Durante mi conferencia un estudiante me planteó una pregunta que se refería a la adecuación y yo le contesté con una paradoja de cómo un aumento de adecuación genética puede no ser adaptativo. Recurrí a un «thought experiment», un 
experimento mental. Se trata de caballos que van evolucionando y esto lleva a la especie a cometer suicidio. Como la tasa de crecimiento de la hierba es una función de cómo es de alta la hierba (pues eso se relaciona con su eficiencia en hacer fotosíntesis), los caballos que son capaces de tener dientes mas afilados, por decirlo así, comen la hierba mejor, la cortan más baja y cuanto más baja la cortan, la tasa de crecimiento de la hierba es menor y la población que se puede mantener es menor, o sea que la evolución va reduciendo la adaptación y eso puede llevar a la extinción. Disociar estos dos conceptos de adaptación y adecuación es complejo. La adaptación y la adecuación no van juntas necesariamente. El estudiante que había hecho la pregunta era Michael Gilpin quien se interesó muchísimo y nos pusimos en contacto. Yo estaba trabajando también en problemas de competencia entre especies hacia entonces, hacia 1970, mientras él era un estudiante en Irvine. Cuando él terminó el doctorado se vino a Davis por un año y medio o dos de posdoctorado, entonces ahí colaboramos, de hecho empezamos a colaborar por correspondencia antes de que él viniera de posdoctorado.

(Ana) Con él tienes unos artículos sobre la teoría neutral, por ejemplo, y sobre modelación y competencia.

(FJA) Modelar la competencia entre especies era el problema que a él le interesaba más de las cosas que yo trabajaba; después conseguí que se interesara también en estos otros asuntos como la teoría neutral.

(Ana) ¿Cuales crees tú que fueron tus mayores influencias, digamos en este período hasta 75 ?

(FJA) Dobzhansky y yo hablábamos continuamente sobre todo tipo de problemas evolucionistas, pero también sobre cuestiones filosóficas; su influencia fue día con día, cotidiana. Con Simpson, de quien también me hago muy amigo, particularmente cuando establece una fundación y yo soy uno de los consejeros de la fundación, lo veo frecuentemente y somos muy amigos hasta que él muere. Nunca publicamos nada juntos, pero Simpson raramente publicaba nada con nadie. Y sí, la influencia es principalmente intelectual y es de él a mí. Mi relación con Stebbins es más bien personal y de colaboración pero intelectualmente yo creo que le influyo más a Stebbins que Stebbins a mí.

(Ana) Y por ejemplo qué ideas consideras tú que tomaste de Simpson.

(FJA) Sus ideas filosóficas o las relacionadas con la evolución, la manera de pensar, aprendí también sobre paleontología. Él estaba interesado como yo en cuestiones como el progreso y la teleología (aunque no lo llamaba teleología y nunca lo discutió explícitamente), explicaciones reduccionistas de la vida y cosas así.

(Ana) Y cuando tú empezaste en este campo de la evolución ¿cuáles consideras que eran los resultados más sobresalientes? 


\section{Francisco J. Ayala: el hombre renacentista de la evolución}

(FJA) Cuando empecé a estudiar, uno de los problemas era el de la distinción entre la adecuación y la adaptación del que hemos hablado anteriormente; otro, el problema de la variabilidad genética que era una controversia exacerbada entre Dobzhansky y H.J. Muller acerca de que si había mucha variación o poca variación.

(Ana) La famosa controversia entre la escuela clásica y la balanceadora, diferentes ideas de cómo explicar la variabilidad en la naturaleza y qué mecanismo mantenía los polimorfismos.

(FJA) Dobzhansky defendía que había mucha variación y otros decían que no, y decían que no porque crearía mucha carga genética. El problema se pudo resolver empíricamente cuando empezaron a existir las maneras de muestrear la variabilidad genética con los métodos enzimáticos. Son problemas muy importantes y vuelvo una vez más al problema de que quiere decir fitness, «adecuación o eficacia," que es lo que maximiza la evolución o lo que avanza durante la evolución.

(Ana) ¿Esta pregunta crees que ha sido una pregunta constante durante toda tu carrera?

(FJA) Experimentalmente me ha ocupado meses en tiempos recientes.

(Ana) $\mathrm{Y}$ este problema de la adecuación, ¿crees que ha sido resuelto?

(FJA) Por lo menos aclarado, porque ya todo mundo que piense sobre esto reconoce que la adaptación es muy distinto de la adecuación relativa de los genéticos. Qué quiere decir adaptación y cómo lo ves es un problema todavía sin resolver completamente y tal vez no tiene solución completa porque una cosa que yo distinguí, y sigo creyendo que es importante distinguir, es entre la adaptación del individuo, los ojos para ver, manos para coger y que se puede un poco pensar en términos de utilidad, de las cosas que son útiles, que se adaptan, que han evolucionado por una selección natural. Pero hay otro problema que es a otro nivel, a un nivel más alto de integración, que es la acción en la población. Se necesitan maneras de medir la adecuación en las poblaciones, y no en los individuos. $\mathrm{Y}$ esto de nuevo se relaciona con todos los problemas investigados junto con Valentine de ver qué factores son los que contribuyen a que las poblaciones mantengan grandes números, y a que haya gran variabilidad genética.

(Ana) Y por ejemplo estos estudios, en particular de Valentine que mencionas, ¿te hicieron cambiar de opinión en alguna cuestión fundamental de tu teoría?

(FJA) No, porque yo en ese momento no tenía ninguna teoría, yo creo que estos eran problemas empíricos y que no se conocía la solución y que había que empezar a investigarlos y modificar teorías explicativas gra- 
dualmente, probándolas. Empiezas con una teoría de esas que dicen que en ambientes estables, uniformes, hay menos variabilidad, empiezas a tratar de descomponer las variables, investigarlo y vas haciendo un paso cada vez, entonces no es una cuestión de cambiar ideas porque yo no tenía ideas claras, o vamos, no tenía ideas definidas de cuál sería la solución; yo siempre creí que habría relación entre el bienestar de la población por así decirlo (lo escribí en mi tesis doctoral), y la hipótesis de que cuanto más variabilidad genética la población va a estar más adaptada al ambiente porque tiene mas plasticidad, más maneras de disfrutar el ambiente y más posibilidades de sobrevivir a cambios ambientales y adaptarse a ellos.

(Ana) Que es un poco también el corazón de lo que Dobzhansky defendía como postulado de la escuela balanceadora, la cantidad de variabilidad genética se debía justo a la capacidad de los organismos para explotar en determinado momento ambientes diferentes. En relación a este problema, ¿te ha convencido la teoría neutral?

(FJA) La gente lo presenta de manera diferente. Es claro que a nivel de aminoácidos, la variabilidad supone que todos los cambios virtualmente son adaptativos, no son neutrales; si algo es neutral a nivel de los cambios sinónimos o de los intrones o de las secuencias intergénicas, es una cuestión debatida, pero evolucionan a tasas diferentes. Lo que la teoría neutral contribuye, y es muy importante, es que se convierte en una hipótesis nula; una hipótesis nula se puede utilizar para muchas aplicaciones prácticas como si fuera válida y esto es una cosa que me llevó mucho tiempo de convencerle a Kimura. Yo le decía, por un lado, que rechazaba la teoría neutral, sin embargo, por otro le decía que era muy útil. El no lo podía comprender porque decía «son ciertas o no son ciertas las cosas de este mundo». Los presupuestos de la mecánica de Newton no son válidos, no son exactos pero sirven muy bien operacionalmente para predecir, como un punto de partida para medir las diferencias. La teoría neutral primero es una hipótesis nula pero también sirve como punto de partida para medir diferencias para ver qué es lo que cuenta en casos particulares si es que no hay evolución neutral; la existencia del reloj molecular no depende necesariamente de la evolución neutral, si hay evolución neutral hay reloj molecular, pero no al revés.

(Ana) Pero es una evidencia importante para la teoría neutral el que sí exista un reloj molecular.

(FJA) No es en absoluto prueba de nada, porque si no hubiera reloj molecular, que en muchos casos no lo hay o es muy malo, eso niega que la evolución sea neutral con respecto a los aminoácidos y en muchos otros aspectos uno puede decir que la teoría neutral tal y como fue formulada por Kimura y tal como implican las palabras, está negada de hecho. No 


\section{Francisco J. Ayala: el hombre renacentista de la evolución}

existe un reloj molecular con las propiedades que predice la evolución neutral; o sea de neutralidad se sigue reloj molecular, de reloj molecular no se sigue evolución neutral, de hecho el reloj molecular se puede utilizar para muchas cosas que sabemos no son neutrales y el hecho de que el reloj molecular tenga tanto ruido prueba que su función no es neutral con respecto a muchos componentes.

(Ana) Has cambiado de opinión en aspectos fundamentales, sobre teorías, o hipótesis que hayas tenido y que a lo largo de tu carrera académica hayas dicho "bueno estaba equivocado, no era como yo pensaba".

(FJA) En teoría científica lo que pasa es que uno modula la manera de pensar a medida que la ciencia avanza pero mis cambios han sido más de ignorancia de aquellas cosas que no sabía, que ahora sé. Con respecto a ciertas controversias más que cambiar de opinión, he modulado mi forma de pensar. Por ejemplo, Kimura nunca dijo que no había selección natural, decía que hay variantes que se seleccionan a nivel molecular, pero también que a nivel molecular hay muchas alternativas que son equivalentes. Con respecto a la variación cualquiera de ellas es importante, si se seleccionan favorablemente con respecto a las que no son favorablemente seleccionadas esto da importancia a la selección negativa, pero entre estas variantes, todas son igualmente favorecidas por la selección natural y entonces una con respecto a otra, todas son neutrales, pero eso es selección natural, por eso llamarlo no-Darwinismo, no se sabe lo que quiere decir.

(Ana) Entonces tu respuesta sería la misma si yo te preguntara si has cambiado de opinión en cosas importantes en tú vida como por ejemplo dejar los hábitos, o dejar España.

(FJA) No, porque la primera situación es un tipo de problema diferente, cierta manera de pensar y de creer y con respecto a volver a España, nunca me lo he planteado seriamente porque creo que no hay razón para que me lo plantee.

(Ana) Y por ejemplo yo he notado que tú te sientes orgullosamente español en el sentido de una educación diferente.

(FJA) Eso si tiene que ver con ser español, sí tiene que ver con una educación diferente, con un estilo de personalidad. Y soy orgullosamente norteamericano también.

(Ana) Y nunca has tenido problema con ser un americano en España o ser un español en América.

(FJA) Que yo tenga conciencia de eso, no.

(Ana) ¿Has tenido o tuviste algún enemigo académico?

(FJA) Evidentemente hay personas con las que uno tiene desacuerdos intelectuales y sin embargo no personales. Por ejemplo, Kimura y yo nos 


\section{Ana Barahona Echeverría}

teníamos mucho cariño. Yo tengo desde un cuadro japonés que es su regalo de mi boda, hasta las felicitaciones de Navidad que me enviaba todos los años con todos los miembros de la familia. Cuando tuvo su nieta, que se llama Hana como mi esposa, él me mandaba todos los años en $\mathrm{Na}$ vidades una fotografía de él con su nieta; después una fotografía de él con los padres de la nieta y la nieta, yo tengo esas fotografías escritas con mucho cariño y sin embargo teníamos desacuerdos en ciertas cosas intelectuales. Relaciones personales que son desagradables he tenido pocas, afortunadamente y que me parece que siempre han sido en una dirección, ha sido con gente que por alguna razón parece tenerme antipatía incluyendo algunos miembros, 2 ó 3, de Davis en los últimos años que estuve ahí. Yo lo interpreto como envidias que se desarrollaron porque yo estaba avanzando y progresando y tenía el éxito que ellos no tenían. Otra relación extraña que no tenía esa razón de envidia o que a lo mejor pudiera serlo también, es con una persona muy notable, con Richard Lewontin. El siempre se ha portado como si él y yo no nos lleváramos muy bien, y es difícil saber porqué y recientemente se lo dijo a mi hijo, (él estaba en el tribunal de examinar de mi hijo) «yo no se porqué yo te ayudo a ti, si yo no me llevo muy bien con tú padre" y mi hijo no sabía eso y vamos, yo tampoco se lo había dicho ni esperaba que Lewontin hiciera una afirmación así, pero hay gente que como los estudiantes de Lewontin, gente cercana a Lewontin que lo sabía y no se porqué. Hay 3 razones que se me ocurren de esa animosidad que aunque yo no se la tenga a él si la reconozco de él hacía mi, y que crea cierto recelo: una de las razones tal vez la más importante es la relación íntima de Dobzhansky conmigo durante sus últimos 14 años; casi desde el día que llegué a su laboratorio le dieron celos. Una manera de pensarlo es celos y sobre todo Lewontin ha dicho que yo llevé a Dobzhansky en direcciones equivocadas en cuestiones de filosofía, la religión y ciertas maneras de pensar; otra razón es que cuando yo terminé el doctorado en 64 , Lewontin me ofreció ir de posdoc a su laboratorio en Chicago a través de Howard Levene, que entonces se ocupaba de mi en Columbia porque Dobzhansky ya estaba en la Universidad Rockefeller. La idea de trabajar con Lewontin me interesó pues lo admiraba mucho y me acuerdo muy bien habérselo mencionado a Dobzhansky y me acuerdo también que él me dijo «pues te vas a quedar aquí, vente a trabajar conmigo de posdoc, para que quieres ir con Lewontin". Entonces decidí por varias razones incluyendo la vida de Nueva York (que era donde yo estaba entonces) quedarme con Dobzhansky en lugar de ir a Chicago; yo creo que eso lo ofendió y le pudo haber ofendido bastante; por muchos años pensé que no, pero quizá le ofendió más de lo que yo pensaba, que yo hubiera preferido trabajar con Dobzhansky en lugar 


\section{Francisco J. Ayala: el hombre renacentista de la evolución}

de ir con el gran Lewontin. Y la tercera razón son 2 ó 3 conflictos de nivel científico. Varios artículos de Lewontin con Hubby, Prakash y otros, sobre todo los primeros, dicen específicamente que la diferenciación entre especies es mínima a nivel de enzimas y que las especies no se pueden distinguir por medio de ellas.

(Ana) Enzimas muy conservadas.

(FJA) O polimorfismos que se sobrelapan, más que conservadas son polimorfismos que se sobrelapan, decía él, tanto que no se pueden distinguir las especies. Esto me pareció a mi tan evidentemente erróneo que sólo lo pude explicar entonces y lo puedo explicar ahora, primero por el hecho de que Lewontin nunca trabajó con los geles él mismo y por lo tanto no se dió cuenta de esas diferencias y, segundo, esto indicaba que no había pensado sobre el asunto claramente. Desde el momento que yo empecé a trabajar con el grupo willistoni y también la comparación entre pseudoobscura y persimilis, era evidente mirando a los geles de qué especie era una banda dada, aún antes de hacer la tarjeta código. De hecho cuando empezamos el estudio de poblaciones naturales de pseudoobscura y de persimilis en poblaciones de California, Sierra Nevada y otros sitios en dónde queríamos estudiar los patrones temporales, lo que Dobzhansky y yo hacíamos era ponerles cada una en un tubito, yo hacía las electroforesis de la madre (las hembras no se pueden distinguir morfológicamente) y después Dobzhansky estudiaba los cromosomas en las larvas. $\mathrm{Al}$ mirar las larvas él identificaba la especie, me daba la clave de qué hembra era de qué especie para que yo entonces separara los datos electroforéticos. Pero enseguida vi que yo podía identificar la especie de cada mosca simplemente mirando los patrones electroforéticos. De hecho durante diez mil moscas o más que estudiamos en ese estadio, tuvimos sólo uno o dos desacuerdos entre la clasificación de Dobzhansky y la mía y en los dos casos él volvió a las larvas y a los cromosomas y Dobzhansky reconoció que eran errores de él; la razón por la que era poco probable que yo me equivocara era porque yo no me basaba en un gene o enzima, sino en varios, cada uno de los cuales es diagnóstico. Decidí escribir un trabajo que se llamaba «Enzymes as diagnostic traits of sibbling species» descubriendo marcadores diagnósticos de especies que no son distinguibles morfológicamente. Publiqué ese trabajo que desde entonces ha tenido mucha influencia, porque sirvió para que mucha gente después utilizara las enzimas para distinguir especies crípticas. Entonces la idea de decirle al gran Lewontin que se había equivocado en una cosa tan fundamental... También tuvimos una controversia al mismo tiempo cuando era yo posdoc, con respecto a las ecuaciones de crecimiento de las poblaciones. Yo había escrito un artículo (que apareció en American Naturalist, me imagino que en el año 66 ó 67 
cuando Lewontin era editor de esa revista) que manipulaba poblaciones en las que podía estimarse $r$ o $K$ y si variaban los factores ambientales podía ser que cambiara la fitness, y esto como parte de mi interés de buscar maneras de medir la fitness de poblaciones de que hablábamos. Como editor de la revista me dijo que el trabajo estaba muy bien, y lo publicarían pero añadió que una de las virtudes de la ecuación logística (como se llama) es que $r$ y $K$ son variables independientes. Yo le escribí que no eran independientes ni mucho menos. Entonces él me escribió una carta de vuelta muy humillada diciendo evidentemente que él no había pensado en serio sobre este asunto porque, y por eso no se había dado cuenta, de que $r$ y $K$ están relacionadas a través de otro parámetro que es un factor que reduce la tasa de $r$ proporcionalmente en la ecuación logística $y$ que es el recíproco de $K$. En cualquier caso, esta controversia como fue privada, me imagino yo que tuvo efectos pero no tan importantes como la de publicar el artículo sobre el uso de enzimas como marcadores diagnósticos de especies no distinguibles morfológicamente. Este artículo tuvo mucha influencia porque de ahí en adelante mucha gente, con toda clase de organismos, organismos marinos, y plantas con las que no se pueden hacer pruebas genéticas, empezó a distinguir las especies crípticas por medio de las enzimas como yo había propuesto y esto se convirtió en rutinario; externamente somos amigos y nos gastamos bromas y hablamos bien pero ha manifestado en varias ocasiones un cierto recelo.

(Ana) No me da la impresión de que seas una persona que va dejando por el camino malas relaciones.

(FJA) No.

(Ana) Más bien parece que tu forma de ser es que si ves que con alguna persona o académicamente en el trabajo, la cosa no va para adelante eres muy político y preferirías no seguir adelante.

(FJA) Si, efectivamente es como veo yo mi personalidad también y por eso diría que esas animadversiones son principalmente uni-direccionadas. Aún así, son muy pocos casos porque ha sido una carrera muy larga, son muchos años de vida y en muchos países.

(Ana) Yo preguntaba a los compañeros de laboratorio si alguna vez te han visto enojado; yo nunca te he visto enojado, bueno te he visto serio, pero no enojado y me han dicho de una sola ocasión, un día que descubriste las moscas de Marcos llenas de hongos y bajaste con el tubito y le pusiste una gritisa, pero no me imagino una situación así de generalizada.

(FJA) Porque ya le había dicho varias veces que los tubos no se podían mantener así porque dañaban a todos los demás y cuando la gente hace cosas que perjudican a los demás, como jefe del laboratorio hay que intervenir. 


\section{Francisco J. Ayala: el hombre renacentista de la evolución}

(Ana) No me imagino que tengas ese tipo de respuestas con mucha gente.

(FJA) El problema con enfadarse es que uno se tiene que desenfadar después, es un trabajo doble.

(Ana) No, pero tienes fama de que eres un buen jefe, muy decente, muy amable, muy pacífico, yo conozco jefes de otras personas que son terribles, que la gente les tiene pánico.

(FJA) Yo no veo ventaja en enfadarse ni como jefe, ni como colega, ni nada, porque, como te decía, si uno se enfada tiene que desenfadarse, trabajo doble.

(Ana) Y obviamente si te pregunto si tú odias a alguien en particular me vas a decir que no, alguien así que te haya hecho la vida imposible, de cuadritos al menos.

(FJA) No

(Ana) Gente con la que has colaborado que te queda un malestar así.

(FJA) Fíjate, eso también es cuestión de suerte, porque hay maneras de colaborar; cada uno hace lo que le parece apropiado y lo que sabe hacer y después de manera razonable y de acuerdo se decide quien es primer autor, segundo autor y yo nunca he tenido problemas en mi vida de ese tipo. Nunca, excepto en un caso en que estábamos de acuerdo al principio y teníamos el trabajo y de pronto el coautor me dice «bueno yo creo que debe ser al revés, que yo debo ser el primer autor," entonces le di muchas razones por las que no me parecía, pero claro, él creía que había contribuido más que yo, y entonces para evitar un problema, le dije que tiráramos una moneda al aire y entonces, como yo siempre tengo un angelito protegiéndome, salí yo primero y ya no más. No tengo problemas normalmente, a mi me parece una actitud bastante generosa poner de primeros autores a colaboradores que no escribieron propiamente el artículo pero que hicieron contribuciones muy importantes. Además, a la gente joven aquí en el laboratorio les viene bien ser primer autor en lugar de que yo lo sea.

(Ana) Claro y de tus colaboradores me imagino que con todos ellos guardas una relación afectiva muy cariñosa, por ejemplo con Valentine.

(FJA) Sí, lo que pasa es que los proyectos se acaban, pero con Valentine nos consideramos todavía amigos, tenemos relaciones muy amistosas. Por ejemplo recientemente escribí un artículo para un libro en honor de su jubilación; sin embargo, hablamos rara vez, porque no surge la oportunidad y vivimos en ciudades distintas. Normalmente yo mantengo relaciones buenas con toda la gente con quien he colaborado.

(Ana) Y los alumnos que pasan por tú laboratorio, los técnicos, se van con una buena impresión. 


\section{Ana Barahona Echeverría}

(FJA) En general sí, aunque a través de muchos años ha habido alguno que he tenido que echar y quejarme de su comportamiento.

(Ana) Mano dura.

(FJA) No demasiado, ese es el problema, mano blanda, pero eso si piensas que a través de mi carrera, yo he tenido más de cien personas en mi laboratorio, entre estudiantes de doctorado y posdoctorado, más técnicos y otras gentes que han pasado por el laboratorio, los problemas con el personal han surgido 2 ó 3 veces a lo sumo.

(Ana) Y para terminar, de los evolucionistas de hoy, descartando a los que ya se murieron, Dobzhansky, Simpson y Stebbins, ¿cuál es al que más admiras? ¿admiras a alguien en especial?

(FJA) Admiro a muchos, hay muchos que han hecho contribuciones muy importantes. Ciertamente Lewontin, ciertamente Kimura quien ya no está con nosotros, pues murió en 1994. A nivel de genética de poblaciones hay mucha gente por ahí que tiene un trabajo muy importante. Sobre evolución molecular y reloj molecular una persona a quien admiro es a Walter Fitch. Pero hay muchos otros también importantes a nivel de teoría de la evolución, gente como George C. Williams que es un pensador muy importante. En campos más concretos, una persona que admiro mucho es $\mathrm{E}$. O. Wilson, aún cuando estoy en desacuerdo con algunas conclusiones y posiciones de él. Una persona que ha contribuido mucho, sobre todo a divulgar ideas, es Stephen J. Gould y que además es buen amigo personal. Gould frecuentemente crea más problemas que soluciones, exagera todo con su riqueza verbal y su exuberancia personal y retórica, que le ha creado serios problemas. No hay, sin embargo, figuras que yo admire, que crea que son comparables a Simpson o Dobzhansky; en las siguientes generaciones lo más cercano sería E. O. Wilson. Su investigación no es la genética de poblaciones, sino la sociobiología, que no es tan semejante a los problemas que me interesan a mí, como es el caso de Dobzhansky o de Simpson. 